\title{
An analytical solution describing the shape of a yield stress material subjected to an overpressure
}

Hovad, Emil; Spangenberg, Jon; Larsen, P.; Thorborg, J.; Hattel, Jesper Henri

Published in:

A I P Conference Proceedings Series

Link to article, DOI:

$10.1063 / 1.4951805$

Publication date:

2016

Document Version

Publisher's PDF, also known as Version of record

Link back to DTU Orbit

Citation (APA):

Hovad, E., Spangenberg, J., Larsen, P., Thorborg, J., \& Hattel, J. H. (2016). An analytical solution describing the shape of a yield stress material subjected to an overpressure. A I P Conference Proceedings Series, 1738, [030049]. https://doi.org/10.1063/1.4951805

\section{General rights}

Copyright and moral rights for the publications made accessible in the public portal are retained by the authors and/or other copyright owners and it is a condition of accessing publications that users recognise and abide by the legal requirements associated with these rights.

- Users may download and print one copy of any publication from the public portal for the purpose of private study or research.

- You may not further distribute the material or use it for any profit-making activity or commercial gain

- You may freely distribute the URL identifying the publication in the public portal 


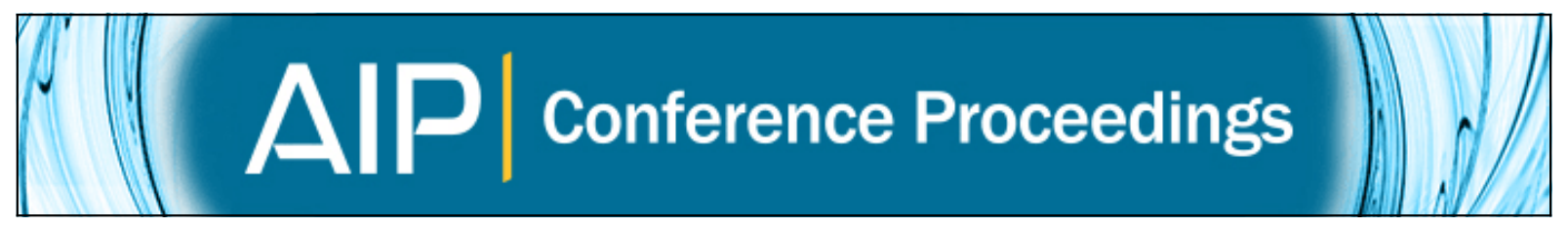

\section{An analytical solution describing the shape of a yield stress material subjected to an overpressure}

E. Hovad, J. Spangenberg, P. Larsen, J. Thorborg, and J. H. Hattel

Citation: AIP Conference Proceedings 1738, 030049 (2016); doi: 10.1063/1.4951805

View online: http://dx.doi.org/10.1063/1.4951805

View Table of Contents: http://scitation.aip.org/content/aip/proceeding/aipcp/1738?ver=pdfcov

Published by the AIP Publishing

\section{Articles you may be interested in}

Influence of Texture and Grain Shape on the Yield Surface in Aluminium Sheet Material Subjected to Large Deformations

AIP Conf. Proc. 1353, 85 (2011); 10.1063/1.3589496

A locally analytic density functional theory describing adsorption and condensation in microporous materials

J. Chem. Phys. 108, 1162 (1998); 10.1063/1.475479

Closed form analytic solutions describing glow discharge plasma

Phys. Plasmas 3, 3842 (1996); 10.1063/1.871516

An analytical expression for describing Auger sputter depth profile shapes of interfaces

J. Vac. Sci. Technol. A 4, 1666 (1986); 10.1116/1.573990

Couette Viscometer Data Reduction for Materials with a Yield Stress

J. Rheol. 29, 369 (1985); 10.1122/1.549818 


\title{
An Analytical Solution Describing the Shape of a Yield Stress Material Subjected to an Overpressure
}

\author{
E. Hovad ${ }^{* \dagger}$, J. Spangenberg*, P. Larsen ${ }^{\dagger}$, J. Thorborg** and J.H. Hattel* \\ *Process Modelling Group, Department of Mechanical Engineering, Technical University of Denmark, Nils \\ Koppels Allé, 2800 Kgs. Lyngby, Denmark. \\ ${ }^{\dagger}$ DISA Industries A/S, Højager 8, Høje Taastr., 2630 Taastrup, Denmark \\ ${ }^{* *}$ MAGMA, Kackertstr. 11, 52072 Aachen, Germany.
}

\begin{abstract}
Many fluids and granular materials are able to withstand a limited shear stress without flowing. These materials are known as yields stress materials. Previously, an analytical solution was presented to quantify the yield stress for such materials. The yields stress is obtained based on the density as well as the spread length and height of the material when deformed in a box due to gravity. In the present work, the analytical solution is extended with the addition of an overpressure that acts over the entire body of the material. This extension enables finding the shape of a yield stress material with known density and yield stress when for instance deformed under water or subjected to a forced air pressure.
\end{abstract}

Keywords: Rheology, Yield stress, Analytical solutions

PACS: $81.05 . J e, 02.60 . \mathrm{Lj}, 47.56 .+\mathrm{r}, 83.10 .-\mathrm{y}$

\section{INTRODUCTION}

Yield stress materials come in many varieties such as green sand [1], concrete [2], and ceramic slurries [? ]. Recently, an analytical solution was derived to determine the yield stress of a given material (i.e. a very fluid concrete also known as a self-compacting concrete) [4]. The solution utilizes the density along with the height $h_{0}$ and spread length $\mathrm{L}$ measured in the LCPC-box test in order to back out the yield stress. The LCPC-box test is performed by pouring 6 liters of material into a box with a height of $0.12 \mathrm{~m}$, a width of $0.2 \mathrm{~m}$, and a length of $1 \mathrm{~m}$, see fig. 1(a-b). This methodology is a cheap low-tech procedure to obtain the yield stress which often is a key parameter when evaluating the flowability of yield stress materials.
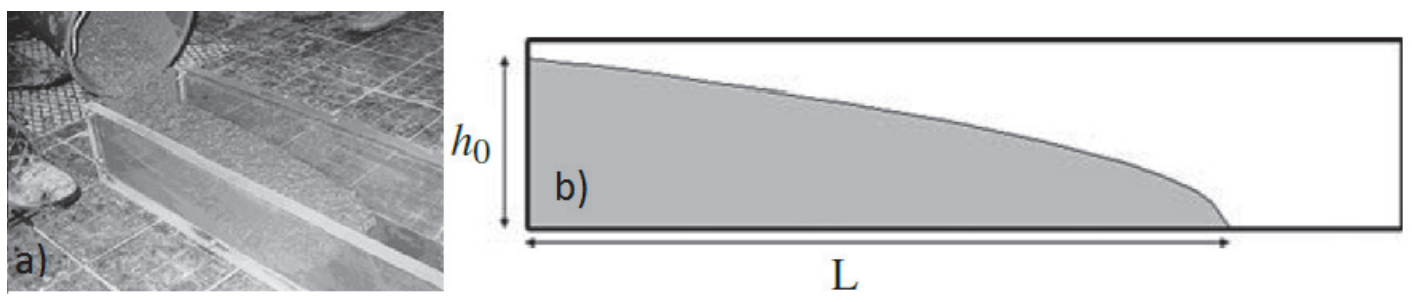

FIGURE 1. (a) LCPC BOX test and (b) height $h_{0}$ and length L in the LCPC BOX test are correlated to the yield stress, figures from [5].

In this paper, the analytical solution is presented with an overpressure. This new solution mimics a situation where the yield stress material deforms for instance subsurface or when exposed to an additional air pressure.The deformation is expressed as the length as a function of the height while the input parameters needed are the density and yield stress. In the following, the new solution is first derived in three- and two dimensions and afterwards plotted for different pressures. 


\section{D ANALYTICAL SOLUTION WITH AN OVERPRESSURE}

The forces acting on an infinitesimal slice of the yield stress material in the LCPC-box comes from the friction at the bottom and side walls, the hydrostatic pressure, and the overpressure, see fig. 2.
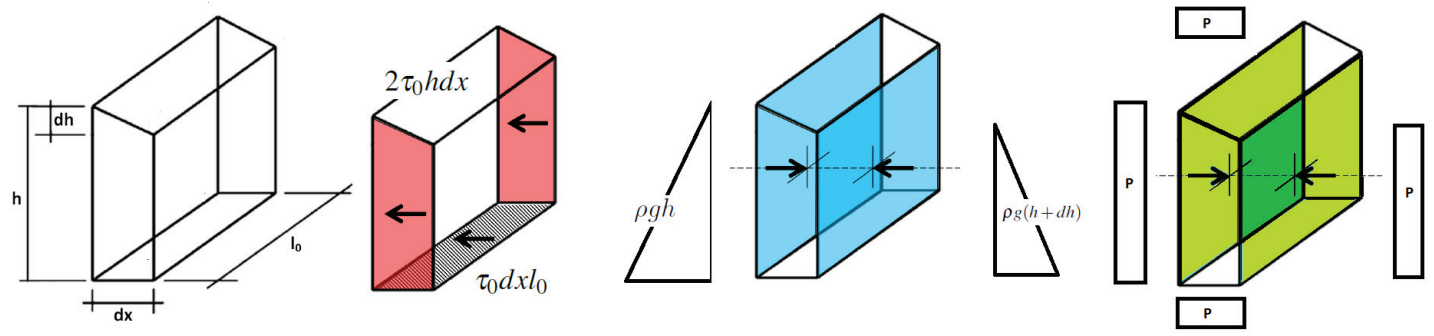

FIGURE 2. An illustration of the friction from the bottom and side walls, the hydrostatic pressure, and the overpressure that act on an infinitesimal slice of the yield stress material in the LCPC-box. The figure is edited from [4] and originates from [5].

The force equilibrium is given by,

$$
\left(P+\frac{1}{2} \rho g h\right) h l_{0}-\left(P+\frac{1}{2} \rho g(h+d h)\right)(h+d h) l_{0}-\tau_{0} d x l_{0}-2 \tau_{0} h d x=0
$$

where $P$ is the overpressure, $\rho$ is the density, $g$ is the gravitational acceleration, $h$ is height, $l_{0}$ is the width of the box and $\tau_{0}$ is the yield stress. Note that the increment $d h$ is negative due to the decreasing height of the material in the box and that the vertical overpressure is eliminated by the reaction force from the bottom and thereby transferred into a horizontal overpressure.

Assuming that $d h^{2}$ is negligible one obtains,

$$
\left(\frac{P}{\rho g}+h\right) \frac{d h}{d x}=-\left(\tau_{0}+2 \tau_{0} \frac{h}{l_{0}}\right) \frac{1}{\rho g}
$$

Solving the differential equation yields the length as a function of the height,

$$
x(h)=\frac{\left(h_{0}-h\right) \rho g l_{0}}{2 \tau_{0}}+\left(\frac{l_{0}^{2} \rho g}{4 \tau_{0}}-\frac{P l_{0}}{2 \tau_{0}}\right) \ln \left(\frac{2 h+l_{0}}{2 h_{0}+l_{0}}\right)
$$

Note that if $P=0$, then the original solution from [5] is obtained $x(h)=\frac{\left(h_{0}-h+\frac{l_{0}}{2} \ln \left(\frac{2 h+l_{0}}{2 h_{0}+l_{0}}\right)\right) \rho g l_{0}}{2 \tau_{0}}$. The integral of the material is given by the following when assuming that $h$ does not vary with $l_{0}$,

$$
V=l_{0} \int_{0}^{h_{0}} x(h) d h=l_{0} \int_{0}^{h_{0}} \frac{\left(h_{0}-h\right) \rho g l_{0}}{2 \tau_{0}}+\left(\frac{l_{0}^{2} \rho g}{4 \tau_{0}}-\frac{P l_{0}}{2 \tau_{0}}\right) \ln \left(\frac{2 h+l_{0}}{2 h_{0}+l_{0}}\right) d h
$$

Based on the initial volume and width and the assumption that $A=\frac{V}{l_{0}}$, one obtains,

$$
A=\int_{0}^{h_{0}} x(h) d h=\frac{\rho g l_{0}}{2 \tau_{0}} \int_{0}^{h_{0}} h_{0}-h+\left(\frac{l_{0}}{2}-\frac{P}{\rho g}\right) \ln \left(\frac{2 h+l_{0}}{2 h_{0}+l_{0}}\right) d h
$$

which yields,

$$
A=\frac{l_{0}}{8 \tau_{0}}\left(2 \rho g h_{0}^{2}-2 l_{0} h_{0} \rho g+4 P h_{0}+\left(2 P l_{0}-g l_{0}^{2} \rho\right) \ln \left(\frac{l_{0}}{l_{0}+2 h_{0}}\right)\right)
$$

Now $h_{0}$ can be found iteratively e.g. with the Newton Raphson method. Utilizing $h_{0}$ in eqn. (3) together with a known viscosity and density facilitates the solution for the deformed yield stress material. 


\section{D ANALYTICAL SOLUTION WITH AN OVERPRESSURE}

In the ideal 2D case, as opposed to the $3 \mathrm{D}$ case, there is no influence from the front and back lateral walls $\left(l_{0} \rightarrow \infty\right)$, see fig. 3 .

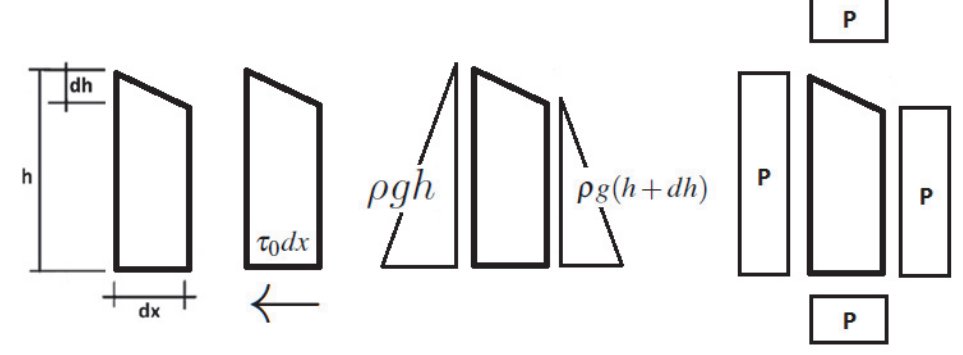

FIGURE 3. An illustration of the friction from the bottom, the hydrostatic pressure, and overpressure that act on an infinitesimal slice of the yield stress material in the ideal 2D case. The figure is edited from [4] and originates from [5].

The force equilibrium is now given by,

$$
\left(P+\frac{1}{2} \rho g h\right) h-\left(P+\frac{1}{2} \rho g(h+d h)\right)(h+d h)-\tau_{0} d x=0
$$

Assuming that $d h^{2}$ is negligible one obtains,

$$
(P+\rho g h) \frac{d h}{d x}=-\tau_{0}
$$

Solving the differential equation yields the height as function of the length,

$$
h(x)=\frac{-P+\sqrt{P^{2}+2 \rho g\left(\tau_{0} L-\tau_{0} x\right)}}{\rho g}
$$

or the length as function of the height,

$$
x(h)=\frac{h_{0}^{2} \rho g}{2 \tau_{0}}-\frac{h^{2} \rho g}{2 \tau_{0}}+\frac{P h_{0}}{\tau_{0}}-\frac{P h}{\tau_{0}}
$$

Note that if $P=0$, then the original solution from [5] is obtained $x(h)=\frac{h_{0}^{2} \rho g}{2 \tau_{0}}-\frac{h^{2} \rho g}{2 \tau_{0}}$.

The integral, giving the area, can be expressed as,

$$
A=\int_{0}^{h_{0}} x(h) d h=\int_{0}^{h_{0}} \frac{h_{0}^{2} \rho g}{2 \tau_{0}}-\frac{h^{2} \rho g}{2 \tau_{0}}+\frac{P h_{0}}{\tau_{0}}-\frac{P h}{\tau_{0}} d h
$$

Solving the integral yields,

$$
A=\frac{\rho g h_{0}^{3}}{3 \tau_{0}}+\frac{h_{0}^{2} P}{2 \tau_{0}}
$$

$h_{0}$ is then given by,

$$
h_{0}=\frac{C^{\frac{1}{3}}}{2 \rho g}+\frac{P^{2}}{2 \rho g C^{\frac{1}{3}}}-\frac{P}{2 \rho g}
$$

Where $C=12 A \tau_{0} \rho^{2} g^{2}+2 \sqrt{6} \sqrt{A \tau_{0}\left(6 A \rho^{2} g^{2} \tau_{0}-P^{3}\right)} \rho g-P^{3}$. Utilizing $h_{0}$ in eqn. (10) together with a known viscosity and density facilitates the solution for the deformed yield stress material. 


\section{Results and Discussion}

The final deformed shapes of a yield stress material obtained with the 3D and 2D analytical solutions are illustrated in Fig. 4. The material properties chosen are a density of $1000 \mathrm{~kg} / \mathrm{m}^{3}$ and a yield stress of $100 \mathrm{~Pa}$. The applied over pressures are $0 \mathrm{~Pa}, 10 \mathrm{~Pa}, 100 \mathrm{~Pa}, 1000 \mathrm{~Pa}$ and $10000 \mathrm{~Pa}$.
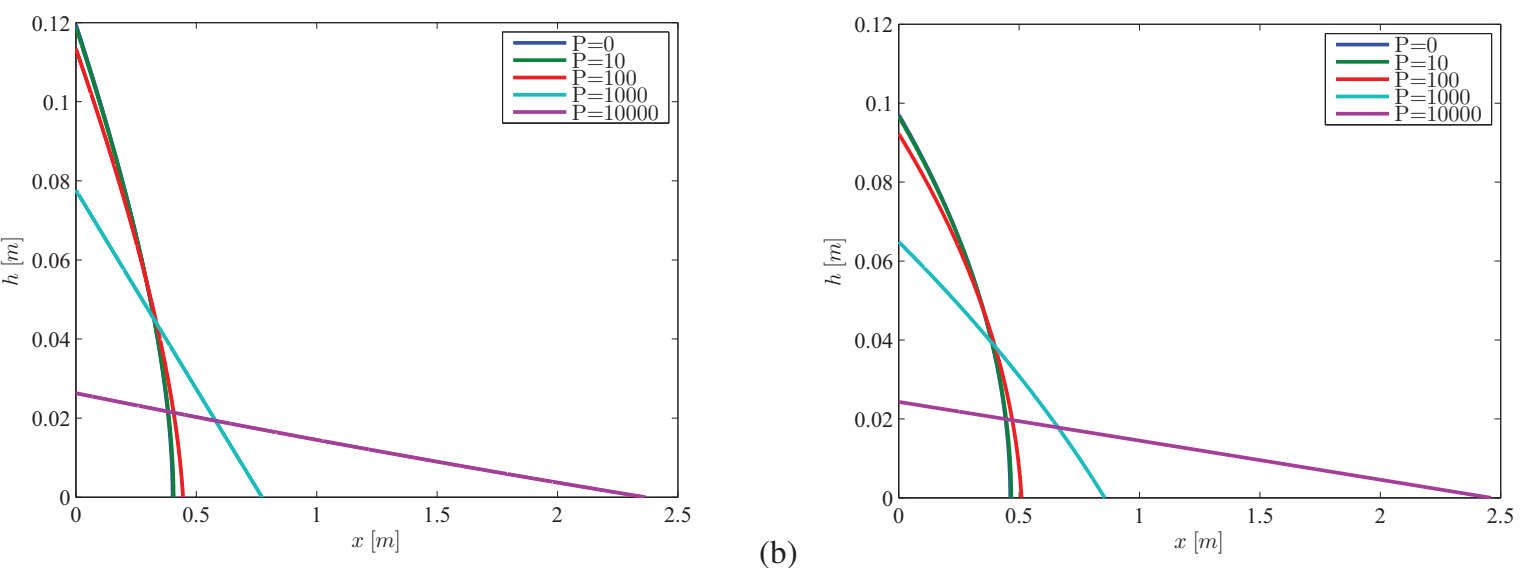

FIGURE 4. Final deformed shapes of a yield stress material obtained with the (a) the 3D analytical solution and an initial volume of 6 liters and a width of $l_{0}=0.2 \mathrm{~m}$, (b) the $2 \mathrm{D}$ analytical solution and an initial area of $0.03 \mathrm{~m}^{2}$ and an infinte width $l_{0} \rightarrow \infty$. The physical settings are the same for the two simulations: a density of $1000 \mathrm{~kg} / \mathrm{m}^{3}$, a yield stress of $100 \mathrm{~Pa}$, and an overpressure that varies between $0 \mathrm{~Pa}$ and $10000 \mathrm{~Pa}$. Note the different length scales on the axes.

Generally the horizontal pressure squeezes out the material, thereby increasing the spread length $\mathrm{L}$ and decreasing $h_{0}$ as seen in fig. 4. For small overpressures, the profile becomes more parabolic, while it becomes more and more linear when the overpressure starts to dominate. The figure also illustrates that the spread length for the 3D solution is somewhat less than for the 2D solution especially for low over pressures, since the 3D solution takes into account the friction at the front and back wall.

\section{CONCLUSION}

In the present work an extension of the original solution in [5] for the shape of a yield stress material under the influence of gravity has been derived with an over pressure. The basic force in both $2 \mathrm{D}$ and 3D equilibrium for an infinitesimal fluid element is established and the resulting differential equations are solved analytically. The final deformation shapes are plotted as a function of distance for increasing values of the overpressure and it is noticed that the shape tranfers from parabolic to a more linear shape for increased values of the overpressure.

\section{REFERENCES}

1. J. Bast, Archives of Metallurgy and Materials 58 (2013).

2. J. Spangenberg, N. Roussel, J. H. Hattel, E. Sarmiento, and M. R. G. G. Zirgulis, Cement and Concrete Research. 42 , 1571 Ü1578 (2012).

3. M. Jabbari, and J. Hattel, Mater. Sci. Tech. 30, 283 Ü288 (2014).

4. J. Spangenberg, PHD-Thesis from Danish Technical University of Denmark (DTU) (2012).

5. N. Roussel, Materials and Structures 40, 1789 Ü1796 (2007). 